\title{
RETICULUM-CELLED MEDULLARY RETICULOSIS IN A YOUNG ADULT
}

\author{
BY \\ F. G. J. HAYHOE \\ From the Department of Medicine, University of Cambridge
}

(RECEIVED FOR PUBLICATION AUGUST 3, 1954)

The clinical picture and histology of the non-lipoid reticulo-endotheliosis of children usually known as Letterer-Siwe disease is well established, but there is dispute as to the origin and nature of the abnormal hyperplastic cells, whether histiocytes or reticulum cells and whether primarily of sinus or medullary origin. These cytogenetic problems have been exhaustively discussed in many publications, notably those of Abt and Denenholz (1936), RobbSmith (1938), Wallgren (1940), Lichtenstein and Jaffe (1940), Mallory (1942), Jaffe and Lichtenstein (1944), Schafer (1949), and McLetchie (1952). The discussions include much speculation on the connexion between Letterer-Siwe disease, HandSchüller-Christian disease, and eosinophil granuloma of bone, but there is little reference to the occurrence of the histological picture of Letterer-Siwe disease in adults. Robb-Smith $(1938,1947)$ refers to reticulum-celled medullary reticulosis in adults as somewhat resembling typhoid fever in clinical course, with splenomegaly, generalized lymphadenopathy, and death usually within a year, while Scott (1951) describes the condition as more chronic than in children, with massive splenomegaly and lymph node enlargement, anaemia, thrombocytopenia, and leucopenia. The latter author mentions a patient relieved for some 18 months by splenectomy and irradiation. Apart from these brief references the literature contains no detailed case reports of the course of this disease in adults, and it is the object of this communication to present such a case history together with an account of the haematological and cytological findings during life and the information obtained from post-mortem examination.

\section{Case Report}

Clinical Course and Investigations during Life.-The patient was a young man aged 19 , a farm worker, whose first complaint was of enlarged axillary glands, noticed in January, 1953. There was no relevant past or family history, no pyrexia or constitutional disturbance, and no further physical signs at this stage other than slight splenomegaly. A chest radiograph showed no hilar enlargement. There was no anaemia, the leucocyte count was $6,200 / \mathrm{c} . \mathrm{mm}$. with normal differential, the sedimentation rate was normal, and the Paul-Bunnell test negative. Histological examination of a lymph node biopsy showed chronic inflammatory changes of a non-specific nature. The condition remained little changed until April, 1953, when increasing lassitude and cough with sputum developed. The spleen was enlarged to the umbilicus and the liver to three fingerbreadths below the right costal margin. Mantoux tests and frequent sputum examinations for tubercle bacilli proved negative, and a chest radiograph showed no pulmonary infiltration although there was some prominence of hilar shadows. Blood examination revealed mild anaemia (Hb 10 g.\%) and a general leucopenia (W.B.C. $1,000 /$ c.mm.); no abnormal or primitive cells were seen. Aspiration of sternal marrow showed high cellularity with hyperplasia of both normoblastic and granulocytic cells, increased mitotic activity, and a suggestion of a granulocyte maturation defect (Figs. 1 and 2). A second attempted lymph node biopsy showed chiefly fatty connective tissue with some inflammatory reaction. In view of the pyrexia, which now ranged up to $103^{\circ} \mathrm{F}$., a blood culture and Widal reaction were carried out; results were negative. Over the next month improvement occurred, the spleen and lymph glands became smaller and cough and dyspnoea diminished. A third axillary gland biopsy was performed in May and once again only chronic inflammatory changes were found; ZiehlNeelsen staining showed no tubercle bacilli. A somewhat fluctuating course was followed until July, 1953, when an attack of varicella supervened. By the end of this infection the clinical state was very poor, with pyrexia of $104^{\circ} \mathrm{F}$., dyspnoea, cyanosis, and gross splenomegaly and hepatomegaly, but a further improvement took place in August, and by the end of this month the spleen and liver could scarcely be felt and the lymph nodes weie much smaller. At this time an eosinophilia developed, rising to a maximum level of 1,000 eosinophils per c.mm. in the blood, and persisted for about three weeks. No further diagnostic information accrued and 


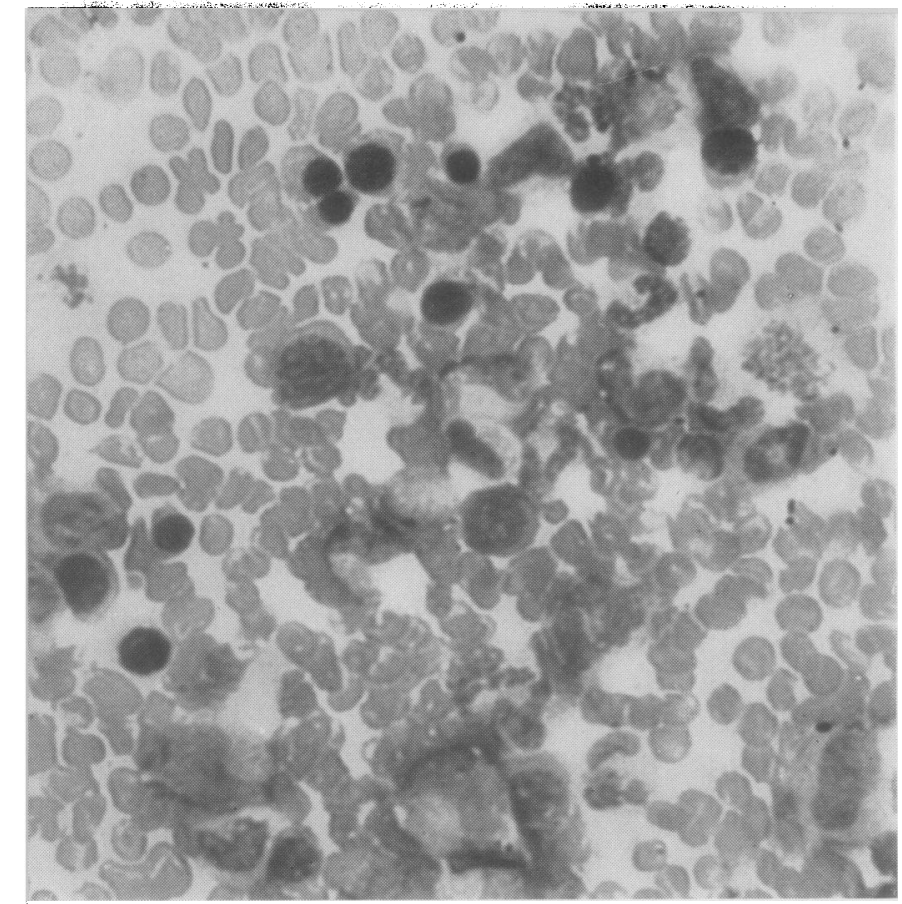

FIG. 1.-Sternal marrow smear showing degree of cellularity in body of film. Leishman, $\times 280$.

the clinical improvement was substantially maintained until November, when a high pyrexia with considerable hepatosplenomegaly and lymphadenopathy recurred. Blood examinations during the next month showed a steady deterioration, $\mathrm{Hb}$ falling gradually from 10.5 g. $\%$ to 7 g. $\%$, leucocytes from 1,200 per c.mm. to 400 per c.mm., and platelets varying between 100,000 and 50,000 per c.mm. During this period an aspiration biopsy of the spleen was performed, but apart from some increase in macrophages no diagnostic information was obtained. A further bone mar-

FIG. 2.-A group of marrow cells of granulocytic and normoblastic series showing normal cytology. Leishman, $\times 500$.

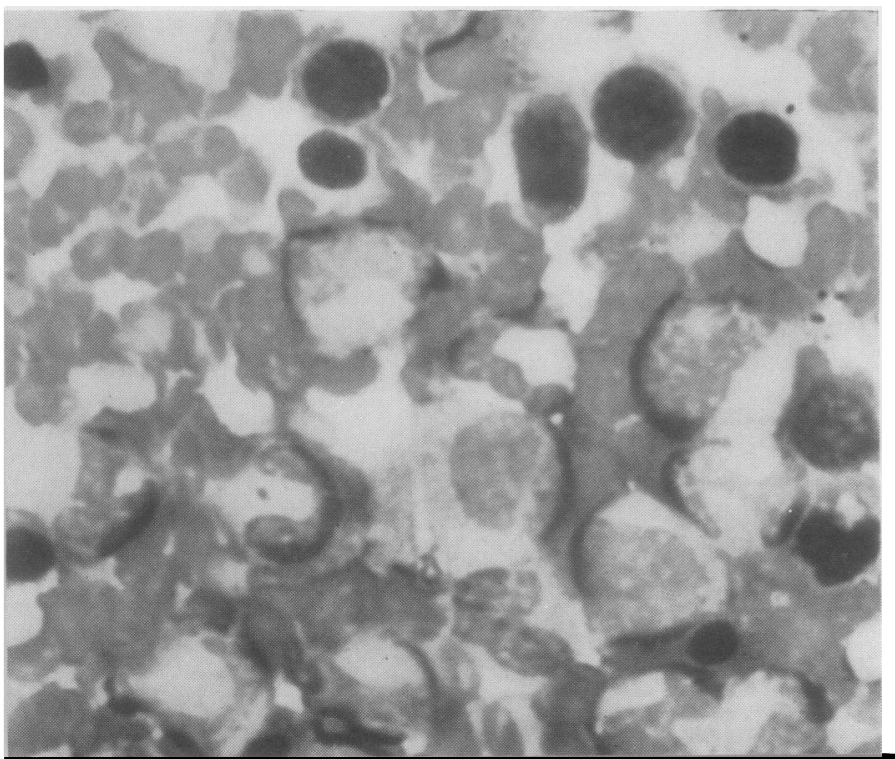

row puncture revealed the persistence of active hyperplasia, with no abnormal cells. The clinical state continued to worsen and the patient died in December, almost a year after the onset of the disease. No firm diagnosis had been made during life, and therapy had initially been directed against a possible tuberculous state. Some encouragement in the use of streptomycin and isoniazid, and, later in the course of the disease, of cortisone, was given by improvements coincidental with treatment, but it seems likely in retrospect that fluctuations in the natural history of the disease were responsible for these misleading impressions, since no drug proved persistently or repeatedly effective.

\section{Post-mortem Examination}

Apart from general pallor of most organs and the presence of scattered bronchopneumonic lesions, the major abnormalities were confined to the lymphatic glands, spleen, and liver.

There was widespread lymphadenopathy, particularly in the abdomen, where paraaortic glands and groups at the hilum of the spleen and at the porta hepatis were prominently enlarged. Cervical, axillary, and inguinal glands showed moderate enlargement. On section the glands varied from white to greyish pink; they were moderately firm in consistency.

The spleen was grossly enlarged (weight $2,300 \mathrm{~g}$.) and rather soft; some follicular structure could be made out on the cut surface, but there was no macroscopically visible infiltrate.

The liver weighed $2,700 \mathrm{~g}$. and was paler than normal; there was a suggestion of increased pallor at the periphery of the lobules.

The bone marrow of the sternum was normal in appearance and there was some extension of pinkish marrow into the upper part of the femoral shafts.

The cardiovascular, gastro-intestinal, urogenital, endocrine, and nervous systems showed no gross abnormality.

\section{Histology of Post-mortem Material}

The lymphatic glands showed histological changes of a uniform character but greatly varying in degree, the changes being least marked in cervical and axillary nodes and most extensive in the abdominal glands. The general architecture of the glands was preserved and recognizable in even the most grossly affected nodes. Many of the follicles contained conspicuous germ centres. The 


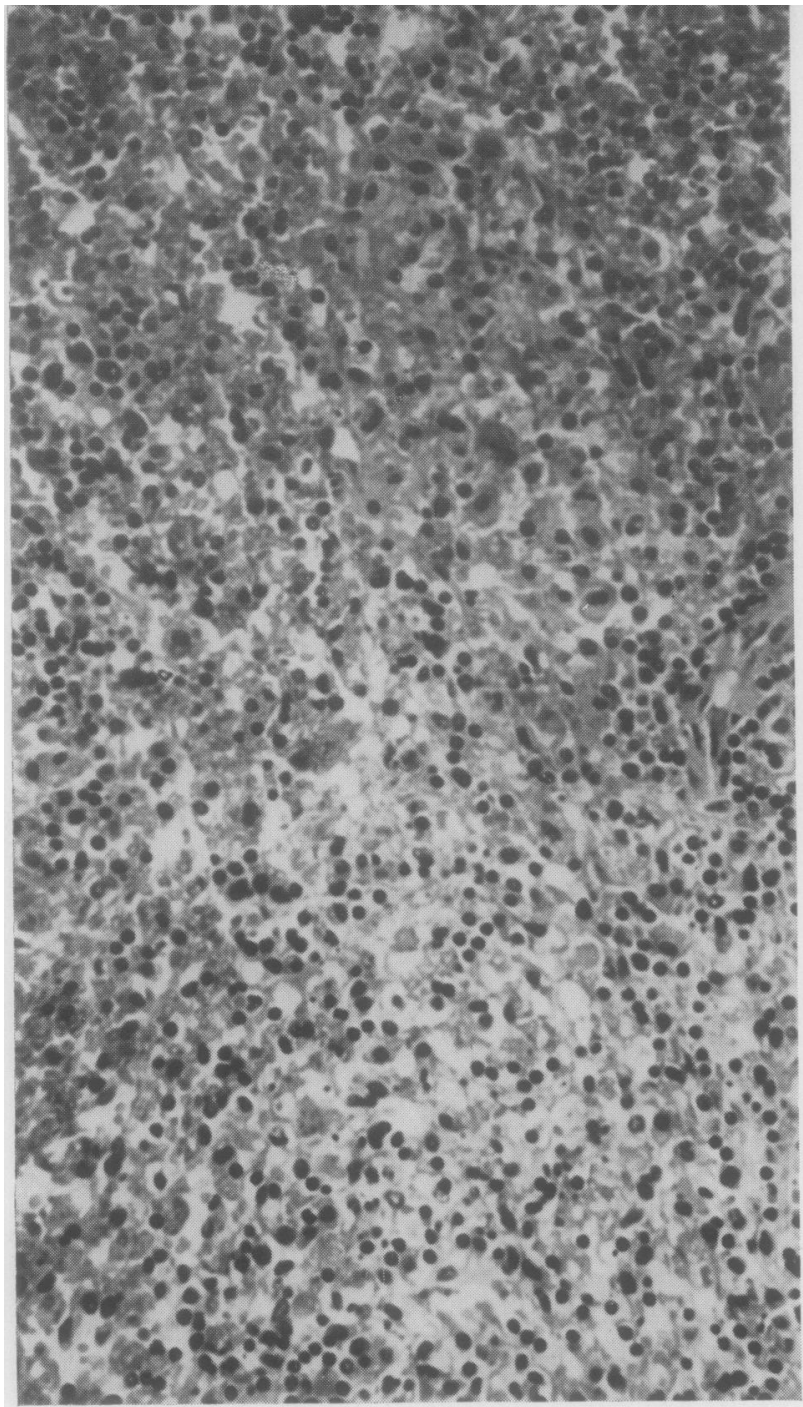

FIG. 6-General view of reticulum cell hyperplasia in spleen. Haematoxy lin and eosin, $\times 140$. main abnormality involved the medullary tissue, where great numbers of large reticulum cells with abundant eosinophilic cytoplasm and often ragged outlines were found compressing the nodes and sinuses. There were some scattered areas of haemorrhage and occasional erythrophagocytosis, but such phagocytosis was infrequent even where considerable extravasation of red cells had taken place. Some of the proliferating reticulum cells were binucleated and cytoplasmic vacuolation was occasionally seen. In some areas there was a tendency to syncytial form, but multinucleated cells of the characteristic Sternberg-Reed type were not present. The lymph node cytology is illustrated in Figs. 3 to 5.

The spleen showed substantially normal architecture, but contained many collections of large cells of similar appearance to those found in the lymph nodes (Fig. 6).

The liver sections showed some fatty change and moderate infiltration with reticulum cells and lymphocytes, particularly in the region of the portal tracts (Figs. 7 and 8).

The bone marrow appearances were within normal limits and no reticulum cell infiltration could be detected (Fig. 9).

Sections of other organs showed no significant relevant abnormality. Bronchopneumonic changes in the lungs and some focal lymphocytic infiltration in the left kidney were noted.

\section{Discussion}

The histological features of this case are those of reticulum-celled medullary reticulosis. There is no lipoid storage and none of the specific clinical or pathological characteristics of Hand-SchüllerChristian disease. Although a transient eosinophilia

FIG. 7.-Focal areas of infiltration in liver. Haematoxylin and eosin, $\times 50$. 
developed at one stage in the disease there is no evidence of eosinophil granulomatosis. The clinical picture and length of course are unlike those of histiocytic medullary reticulosis, and there is no evidence of the very active histiocytic erythrophagocytosis found histologically in this disease. The normal bone marrow findings exclude the group of disorders described by Israëls (1951) under the name of myeloid reticulosis and the many varieties of aleukaemic leukaemia. Such cases as those of Evans, Cipriano, and Ferrell (1949) and Keech and Scott (1953) illustrate the points of resemblance between stem-cell leukaemias and aleukaemic reticulo-endothelioses and many case reports in the earlier literature fall into such intermediate categories. Goldzieher and Hornick (1931) and Dameshek (1933) reviewed over 20 such cases, but Schafer (1949) could find no convincing evidence in previous reports that the reticulo-endotheliosis of adults was the same disorder as infantile non-lipid reticulo-endotheliosis. It is clear that innumerable transitional forms occur intermediately between the classical diseases of the haemopoietic and reticuloendothelial systems. This is to be expected in systems containing many undifferentiated cells of multiple developmental potentialities, and it is therefore the more interesting to note in the present case the absence of confusing involvement of many cell types and the relative simplicity of the cytological picture.

\section{Summary}

A young man of 19 years succumbed to an illness characterized by lymph node enlargement, splenomegaly, hepatomegaly, pyrexia, moderate anaemia, leucopenia, and thrombocytopenia. The bone marrow cytology was within normal limits, lymph node biopsies and splenic puncture failed to establish the diagnosis, and the disease pursued a fluctuating course to its termination one year after the onset. Histological examination of post-mortem material showed reticulum-celled medullary reticulosis.

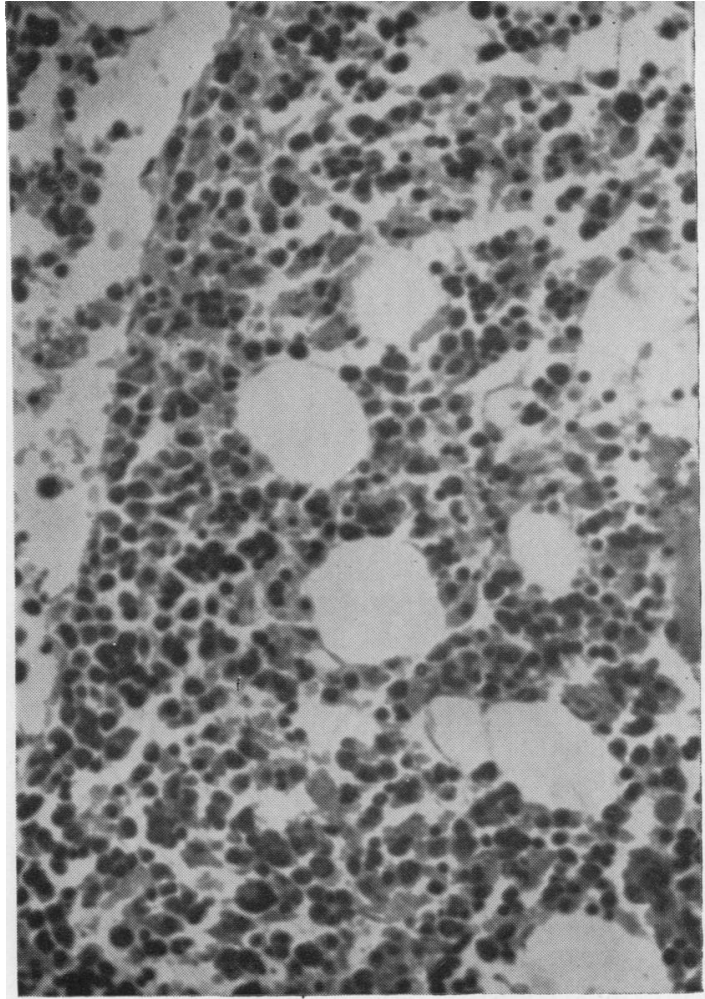

FIG. 9

I wish to record my indebtedness to Dr. Arden Jones, who referred this patient; to Dr. A. M. Barrett and his staff, who performed the post-mortem examination and prepared the sections; and to Sir Lionel Whitby for his constant interest and advice.

\section{REFERENCES}

Abt, A. F., and Denenholz, E. J. (1936). Amer. J. Dis. Child., 51, 499. Dameshek, W. (1933). Folia haemat., Lpz., 49, 64.

Evans, T. S., Cipriano, A. P., and Ferrell, E. H., Jr. (1949). Conn. St. med. J., 13, 1128.

Goldzieher, M.A., and Hornick, O. S. (1931). Arch. Path., Chicago, 12, 773 .

Israëls, M. C. G. (1951). Lancet, 1, 978.

Jaffe, H. L., and Lichtenstein, L. (1944). Arch. Path., Chicago, 37, 99.

Keech, M. K., and Scott, F. E. T. (1953). J. Path. Bact., 65, 79.

Lichtenstein, L., and Jaffe, H. L. (1940). Amer. J. Path., 16, 595.

McLetchie, N. G. B. (1952). Amer. J. clin. Path., 22, 520.

Mallory, T. B. (1942). New Engl. J. Med., 227, 955.

Mabb-Smith, A. H. T. (1938). J. Path. Bact., 47, 457.

Robb-Smith, A. H. T. (1938). J. Path. Bact., 47, 457. (1947). In S. C. Dyke's Re
p. 350. Churchill, London.

Schafer, E. L. (1949). Amer. J. Path., 25, 49

Scott, R. B. (1951). Brit. J. Radiol., 24, 475

Wallgren, A. (1940). Amer. J. Dis. Child., 60, 471.

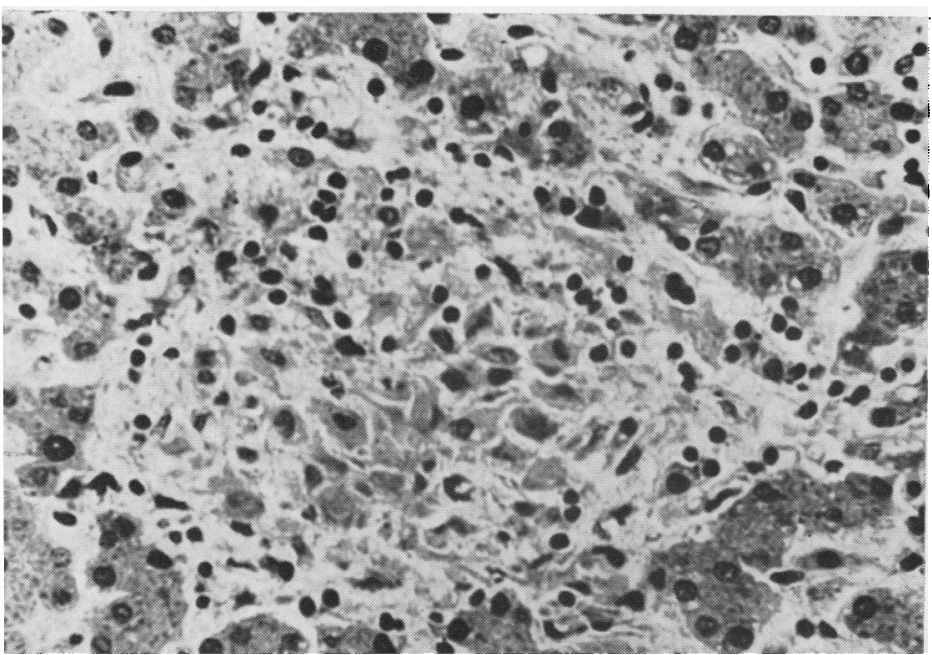

Fig. 8.-Cytology of a focus of reticulum cell and lymphocyte infiltration in liver. Haematoxylin and eosin, $\times 186$.

FIG. 9.-Section of rib showing norma marrow cellularity. Haematoxylin and eosin, $\times 280$. 